\title{
DE BETEKENIS VAN DE LOONPOLITIEK VOOR DE WERKGELEGENHEID.
}

Door Prof. Dr. J. Tinbergen.

\section{Inleiding. Verschillende vraagstukken.}

Het is de bedoeling van dit artikel de invloed van het loonpeil op de werkgelegenheid duidelijk te maken. Deze kwestie heeft reeds geruime tijd de vakbeweging, de regering en de economen van vele landen bezig gehouden.

Het gaat hier om een vrij ingewikkeld verband; het loon beïnvloedt de werkgelegenteid langs verschillende wegen en deze gedeeltelijke invloeden werken elkaar tegen. Daardoor is zelfs de richting van het totale resultaat dezer invloeden niet bij voorbaat met zekerheid vast te stellen. Bekend zijn dan ook de discussies uit de jaren van de grote depressie tussen de vakbeweging enerzijds en de werkgevers en deskundigen anderzijds. Het in de kringen van de economische deskundigen gebruikelijke standpunt, dat ook door de werkgevers en de regering werd ingenomen, was dat verlaging van het loon de werkgelegenheid vergroot, in het bijzonder als gevolg van de kosten- en prijsverlaging welke er door wordt bewerkt. Het is, zoals vaak werd uitgedrukt, naar de mening van deze deskundigen slechts een bijzonder geval van de algemene wet van de vraag, die toch ook zegt dat bij prijsdaling van een goed of dienst, de vraag daarnaar toeneemt. Daartegenover werd van vakbewegingszijde betoogd, dat een daling van het loon de koopkracht van de arbeiders vermindert en dat dientengevolge geen vergroting van de werkgelegenheid optreedt. Men kan ten aanzien van het standpunt van de economen uit die tijd overigens opmerken, dat er op de wet van de vraag uitzonderingen bekend waren.

Een eerste poging tot het brengen van een zekere orde in deze discussie is verricht door de bekende econometrist Jacob Marschak in zijn kleine boekje: Die Lohndiskussion van 1932. Daarin geeft hij een systematische opsomming van de vele wegen waarlangs het loon op de werkgelegenheid invloed uitoefent. Na Marschak's bij- 
drage heeft zich de discussie verder voortgezet en verfijnd, waardoor de mogelijkheid is geschapen om de tegenover elkaar staande standpunten door zorgvuldige analyses en metingen nader tot elkaar te brengen. Het blijkt daarbij dat in elk geval onderscheid moet worden gemaakt tussen een reeks van uiteenlopende probleemstellingen, zoals zo vaak in discussies. Zolang men over twee verschillende probleemstellingen spreekt is het geen wonder, wanneer men het niet eens wordt. Thans wordt vrijwel algemeen ingezien, dat inen tenminste onderscheid moet maken tussen:

1) gevolgen van tijdelijke aard, gevolgen op korte en op lange termijn.

Onder gevolgen van tijdelijke aard zullen wij de gevolgen verstaan van speculatieve aard, waaronder in het bijzonder de verwachting van een verdere daling der prijzen, indien zich een eerste daling heeft voorgedaan als gevolg van een loondaling. De invloed van deze verwachting is er een van terughouding, zoals men dat kent in de neergaande phase van de conjunctuur. Deze invloed is uiteraard maar tijdelijk.

Onder de invloeden, die op korte termijn werken, worden voorts vooral bedoeld de reeds hierboven genoemde invloeden op de kasten van productie en op de koopkracht der arbeiders, zowel als op die van andere bevolkingsgroepen. Deze zijn bij de conjunctuurbewegingen het belangrijkst.

Sprekende over de gevolgen op lange termijn denkt men veelal aan de gevolgen van een loonstijging voor de rationalisatie van de productie of ook aan de gevolgen van een loondaling strekkende tot verlangzaming van dit proces; deze zijn eerst na jaren van merkbare betekenis;

2) de invloed van een loondaling in een gesloten land en een loondaling in een land met buitenlandse handel.

Een loondaling zal in het laatste geval mede kunnen leiden tot een verhoging van de buitenlandse afzet en dientengevolge vermoedelijk een sterkere invloed hebben op de verhoging van de werkgelegenheid dan in het eerstgenoemde geval;

3) reëel loon en geldloon.

Een daling van bv. $10 \%$ in het geldloon zal o.m. ook leiden tot een daling van de kosten van levensonderhoud van zegge bv. $3 \%$. D.w.z. dat het reële loon slechts $7 \%$ daalt. Zou hiermee een verhoging van de werkgelegenheid van bv. $3 \%$ corresponderen, dan kan deze zowel vergeleken worden met de 
verlaging van $10 \%$ in het geldloon als met de verlaging van $7 \%$ in het reële loon.

Het is echter niet voldoende dat de verschillende afzonderlijke invloeden, die uitgaan van een loondaling op de werkgelegenheid, kwalitatief worden onderscheiden; men moet ze ook kunnen meten om te komen tot een inzicht in het totale resultaat. In dit artikel zal gepoogd worden de quantitatieve gevolgen van een loonsverhoging voor de werkgelegenheid nader aan te geven. Daarbij is het in het bijzonder de bedoeling er de aandacht op te vestigen, dat een loonsverhoging meestal niet op zichzelf zal staan, maar aanleiding zal kunnen zijn tot. gelijktijdige andere maatregelen van economische politiek. Met name in de tegenwoordige omstandigheden zal de regering gedwongen zijn maatregelen te nemen t.a.v. de betalingsbalans, terwijl aan de andere kant bij de jongste loononderhandelingen veel aandacht is gegeven aan de mogelijke stijging van de arbeidsproductiviteit. Welke uitwerking zal onder deze omstandigheden een loonsverhoging hebben op de werkgelegenheid? Dit is de vraag die ons hier in 't bijzonder bezig houdt en in $\S 3$ en $\S 4 \mathrm{zal}$ worden besproken, nadat ter inleiding in $\S 2$ de invloed van het loonpeil op de werkgelegenheid zonder deze complicaties zal worden besproken.

\section{De invloed van de loonvoet onder overigens gelijke omstandig-} heden.

Wij zullen eerst trachten na te gaan welke invloed de loonvoet heeft op de werkgelegenheid wanneer er niet tegelijkertijd of als gevolg daarvan andere maatregelen van economische politiek worden genomen. Dit wil dus niet zeggen dat alle andere economische verschijnselen gelijk blijven; de automatische gevolgen van de loonsverhoging voor prijzen, inkomens, in- en uitvoer moeten natuurlijk in acht worden genomen. Doch maatregelen als belastingpolitiek, devaluatie en autonome prijspolitiek worden verondersteld niet plaats te grijpen.

Dit is het vraagstuk dat in de literatuur gewoonlijk wordt behandeld. In Nederland heeft zich bv. het rapport van de CommissieVan der Waerden uit de Hoge Raad van Arbeid (Onderzoek naar de blijvende werkloosheid en haar bestrijding, 's-Gravenhage 1939) daarmede bezig gehouden en met grote nauwkeurigheid getracht vast te stellen met hoeveel procent de werkgelegenheid zal ver- 
anderen als gevolg van een gegeven loonsverhoging. Het resultaat was dat, afgezien van de tijdelijke invloeden, een loonsverhoging van zegge $5 \%$ de werkgelegenheid met ten hoogste ca $5 \%$ zou doen dalen. Bij deze berekening werd de invloed van de uitvoer tevens in acht genomen, hetgeen voor een land als Nederland ook noodzakelijk is; vermoedelijk echter is deze invloed te hoog aangenomen.

Een tweede publicatie in Nederland op dit terrein is het proefschrift van Dr. H. J. Witteveen (thans hoogleraar aan de Nederlandse Economische Hogeschool), getiteld Loonhoogte en Werkgelegenheid (Haarlem 1947), dat betrekking heeft op de Verenigde Staten. Voor dit practisch als een gesloten land te beschouwen gebied vond Professor Witteveen een zeer geringe elasticiteit naar de vraag van arbeid t.o.v. het loon. Daarbij werden zowel de tijdelijke invloeden als de invloeden op lange termijn buiten beschouwing gelaten.

Een meer abstract resultaat was dat van Paul $\mathrm{H}$. Douglas in zijn Theory of Wages (Chicago, 1934). Diens onderzoek, waarvan men kan zeggen, dat het de invloeden op lange termijn mede inbegrijpt, doch op een enigszins meer abstracte wijze, leidde tot het inzicht, dat een daling van het reële loon met $1 \%$ een stijging van de werkgelegenheid met $4 \%$ tengevolge zou hebben. Een zeer hoog cijfer dus. Dit cijfer schijnt in tegenspraak met het vorige. Doch dit is niet met zekerheid te constateren. Wij zagen reeds dat met een geldloondaling altijd een procentuele geringere daling van het reële loon gepaard gaat. Dit betekent dat met de daling van $1 \%$ van het reële loon, waarvan Professor Douglas uitgaat, in de Verenigde Staten een daling van het geldloon met mogelijk $2 \%$ correspondeert. Dit zou volgens het Nederlandse onderzoek reeds tot een daling van de werkgelegenheid van wellicht $2 \%$ leiden. Daar Douglas bovendien nog rekening houdt met de invloed op lange termijn, is het dus niet verwonderlijk dat zijn cijfer hoger ligt. Niettemin is het in vergelijking met de uitkomsten van Prof. Witteveen een hoog cijfer. Deze laatste verwaarloost echter, zoals gezegd, opzettelijk de invloeden op lange termijn.

Deze en soortgelijke uitkomsten kan men zich verduidelijken door een nauwkeurige studie van zeer eenvoudige situaties, van waaruit men allengs meer gecompliceerde gevallen beziet. De laatste geven de realiteit beter weer, maar zijn niet gemakkelijk te begrijpen. Hun behandeling dient overgelaten te worden aan vakspecialisten, 
die ook hun resultaten kunnen mededelen. Goed gekozen eenvoudige gevallen zijn echter wel in staat de werkelijkheid te benaderen.

Ter illustratie geven wij de behandelingswijze weer die Keynes van dit vraagstuk geeft ${ }^{x}$ ). Terecht kan men zich afvragen of deze niet te eenvoudig is. $\mathrm{Zij}$ wordt echter door nader onderzoek in menig opzicht ondersteund. $\mathrm{Z}_{\mathrm{ij}}$ is bedoeld voor een gesloten land.

Zijn inzichten daarover leiden tot twee merkwaardige consequenties. Hij is van mening dat (a) de totale vraag naar goederen en diensten onaf hanelijk is van de hoogte der prijzen en daarom ook van de hoogte der lonen, doch slechts van de hoogte van het reële inkomen. De totale vraag, en daarmede dus ook de werkgelegenheid, wordt bepaald door de gewoonten die er bestaan t.a.v. het uitgeven van het reële inkomen. Laten de totale uitgaven van een bepaald land, die onafhankelijk van het inkomen geschieden, bij een gegven stand der lonen en prijzen 3 milliard zijn; wij denken daarbij aan de allernoodzakelijkste uitgaven voor bv. voeding en huur. Laat verder elke vermeerdering van inkomen met 1 milliard leiden tot een vermeerdering van uitgaven van $3 / 4$ milliard. Dan zullen de totale uitgaven van het land zich instellen op 12 milliard. Slechts dan is er nl. evenwicht tussen uitgaven en inkomsten. Dat ziet men uit onderstaand tabelletje (cijfers in mld gld):

$\begin{array}{ccc}\text { Inkomen } & \text { Uitgaven } & \\ 0 & 3 & \\ 4 & 6 & \\ 8 & 9 & \\ 12 & 12 & \text { evenwicht } \\ 16 & 15 & \end{array}$

Deze cijfers moeten voorts aldus begrepen worden dat zij alleen gelden bij een bepaalde koopkracht van het geld. Zou deze bv. half zo groot worden, dan zouden de uritgaven onafhankelijk van het inkomen automatisch $f 6$ mld worden en daardoor het evenwichtsinkomen ook f 24 mld. Het zouden de reële welvaartsmogelijkheden zijn die bepalend zouden zijn voor de hoagte van de werkgelegenheid.

Het tweede inzicht (b) door Keynes geformuleerd is dat een loonsverhoging een evenredige príjsverhoging tot gevolg heeft. D.w.z. dat het reële loon daardoor niet wordt gewijzigd. De merkwaardige conclusie is dus deze, dat weliswaar een nominale loonsverhoging geen invloed heeft op de werkgelegenhcid, en in zoverre ongevaarlijk is, maar evenzeer dat zij het reële loon niet verbetert en er dus ook weinig redenen zijn, een nominale loonsverhoging na te streven.

Dit beeld is uiteraard iets te sterk vereenvoudigd. Het gaat bovendien uit van de veronderstelling dat er geen zgn. geldillusie bestaat. Zou men aannemen dat deze wel bestaat, d.w.z. dat men zich eerder door zijn geldinkomen dan door zijn reële inkomen laat leiden bij het bepalen van de besteding van het inkomen, dan zouden de gedachten van Keynes betekenen, dat niet zozeer het reële inkomen onafhankelijk is van de hoogte van prijzen en lonen, doch het geldinkomen. In het bovengegeven voorbeeld zou dan ook bij daling van

1) Voor goed begrip van wat volgt is deze passage in kleine letter echter overbodig. 
de koopkracht het evenwichtsinkomen f 12 mld blijven. Wordf onder deze omstandigheden het loon met $1 \%$ verhoogd, dan gaan de prijzen ook omhoeg, zeggen we bv. met $1 / 2 \%$, omdat in een gesloten land de helft der kosten loonkosten zijn. Daar nu krachtens de veronderstelling de totale uitgaven, in geld uitgedrukt, niet zijn gewijzigd, zal er $1 / 2 \%$ minder aan goederen en diensten worden gekocht. De loonsverhoging met $1 \%$ leidt dan tot en werkloosheid van $1 / 2 \%$.

Deze redeneringen hebben echter steeds betrekking op een gesloten land en zijn wel iets tè eenvoudig. Van doorslaggevende betekenis is voor ons wat er in een open land, een land met buitenlands handelsverkeer, geschiedt. Bovendien gedraagt men zich bij de besteding van zijn inkomen toch nog wel iets anders dan door Keynes is aangenomen, al is zijn veronderstelling een zeer treffende eerste benadering van de werkelijkheid.

Het vraagstuk blijkt nu veel ingewikkelder te worden, in feite te ingewikkeld voor behandeling in een artikel als het onderhavige. Daarom moge slechts worden medegedeeld dat een nadere berekening ${ }^{2}$ ) tot het inzicht leidt dat een nominale loonsverhoging van $10 \%$, zonder andere maatregelen, de werkgelegenheid verlaagt met 0,8 à $3 \%$. De uitkomsten variëren al naarmate men uiteenlopende cijfers aanneemt voor de reactie van prijzen op lonen, van in- en uitvoer op prijzen en van uitgaven op inkomens. Tevens gaat daarmee gepaard een verhoging van het deficit op onze betalingsbalans van f 100 à f $200 \mathrm{mln}$. Invloeden op langer termijn dan enkele jaren zijn echter, zoals reeds opgemerkt, daarbij verwaarloosd.

De berekeningen wijzen tevens uit dat in zeldzame situaties, nl. in geval van diepe depressie, het inderdaad kan gebeuren dat een loonstijging de werkgelegenheid niet doet dalen. Het vakverenigingsstandpunt in de bekende discussie, hiervoor aangehaald, blijkt dan dus juist te zijn. Het blijkt dan juist te zijn, omdat in een dergelijke situatie het overbrengen.van koopkracht van hen die deze oppotten naar hen die haar niet oppotten de doorslag geeft tot ondersteuning van de totale vraag.

3. Loonpolitiek onder gelijktijdige handhaving van de betalingsbalanspositie.

Wij dienen echter het vraagstuk in het kader te zien van de politieke werkelijkheid. Het is niet zo, dat de loonpolitiek kan

$\left.{ }^{2}\right)$ Deze zal worden gepubliceerd in Econometrica onder de titel: „Wage policy and devaluation: their influence on the balance of payments and employment". 
worden bedreven zonder repercussies bij de andere economischpolitieke beslissingen. $\mathrm{Er}$ is in de realiteit een spel van actie en reactie tussen een aantal groepen en machten. Naast de arbeiders zijn er de boeren, de overige ondernemers, de regering (in het bijzonder de financiële autoriteiten), die elk hun eigen verantwoordelijkheid en doeleinden hebben. Ook heeft de vakbeweging de mogelijkheid om niet alleen op de lonen invloed uit te oefenen; daarnaast kan zij in zekere mate de productiviteit mede bepalen, al zijn hier de ondernemers mede van grote betekenis.

In de huidige omstandigheden - of beter die van de komende paar jaar - is daarbij de noodzaak voor de Regering om de betalingsbalans in evenwicht te brengen van bijzondere betekenis. Wij willen zien in hoeverre dit op de gevolgen van het loon voor de werkgelegenheid invloed heeft.

Loonstijging beïnvloedt $\mathrm{nl}$. de betalingsbalans ongunstig: zij verhoogt de kosten, dus de prijzen en vermindert daardoor de concurrentiepositie op de internationale markt. $Z_{i j}$ verlaagt de export; weliswaar staat daar een geringe verlaging van de invoer tegenover, voorzover. de werkgelegenheid en het nationale inkomen er door verminderen, doch in het algemeen overweegt de eerste factor. Loonstijging zal daardoor op den duur moeten leiden tot maatregelen van de financiële autoriteiten ter bescherming van de betalingsbalans. Hoe zullen deze maatregelen op de totale omvang van de productie werken?

Om deze vraag te kunnen beantwoorden moeten wij een ogenblik dieper ingaan op de eisen van het betalingsbalansevenwicht. Het deficit op de betalingsbalans is gelijk aan het verschil tussen invoer en uitvoer. Door een loonstijging, zegge van $1 \%$ zal een prijsstijging optreden van $0,3 \%$, aangezien in Nederland het aandeel van de loonkosten in de prijs der producten gemiddeld op $30 \%$ kan worden gesteld. Deze prijsstijging zal zijn uitwerking doen gevoelen op de invoer zowel als op de uitvoer. Het is bekend uit vroegere statistische onderzoekingen ${ }^{3}$ ) dat het volume van de invoer daardoor een stijging van ca $0,1 \%$ zal ondergaan. Het volume van de uitvoer ${ }^{4}$ ) zal daartegenover een daling van ongeveer $0,6 \%$ ver-

3) J. Tinbergen, „De schommelingen van de invper, 1923-1938”, Stat. en Econometr. Onderz. 1948, afl. 2, blz. 52.

\) Vgl. J. B. D. Derksen en A. L. G. M. Rombouts, De invloed van het prijsniveau op de uitvoer, De Nederlandsche Conjunctuur, Speciale Onderzoekingen no. 1. 
tonen, $\mathrm{nl}$. het dubbele van de prijsstijging. Voor de betalingsbalans is echter van betekenis wat er geschiedt met de in geld uitgedrukte in- en uitvoer. De prijzen van de invoer worden door de loonsverhoging niet beïnvloed. De invoer zal dus naar waarde eveneens met $0,1 \%$ stijgen. De uitvoer daarentegen zal naar waarde slechts met $0,3 \%$ dalen, aangezien tegenover de daling van de hoeveelheid een stijging van $0,3 \%$ van de prijzen staat. Daar voorts de waarde van de uitvoer van goederen en diensten voor het jaar 1949 wordt geraamd op ca $90 \%$ van die van de invoer, wordt de betalingsbalans ongunstiger tot een bedrag van $0,1+0,3 \times 0,9=0,37 \%$ van de invoerwaarde. In het door ons veronderstelde geval zal nu door tegen-maatregelen worden zorg gedragen voor een compensatie voor deze achteruitgang in de betalingsbalanspositie. Deze kunnen of wel de vorm aannemen van een verlaging der subsidies of eventueel andere vormen, doch zullen altijd moeten neerkomen op een verlaging van ons activiteitspeil, daar dit de enige mogelijkheid is (behalve de juist hiervoor beschouwde loon- en prijspolitiek) om onze invoer te beïnvloeden. Blijkens onze voorafgaande cijfers is een verlaging van onze activiteit met $0,37 \%$ nodig om dit evenwicht te herstellen. Dit betekent, dat op deze wijze tengevolge van de loonsverhoging van $1 \%$ een verlaging van de productie, dus ook van de werkgelegenheid, met ca 0,37\% moet worden verwacht.

In het voorafgaande betoog werd aangenomen dat slechts de financiële autoriteiten als tegenspelers tegenover de loonpolitiek zouden optreden. In werkelijkheid is het veel gecompliceerder. Behalve de vakbeweging, die loonpolitiek voert, en de regering, die voor de betalingsbalans moet waken, zijn er andere groepen van de bevolking die voor hun belangen opkomen, waarbij als voorbeelden mogen worden genomen de landbouw, de middenstand en de industrie. Deze zullen in het algemeen pogen om de prijzen te verhogen, niet slechts als in het voorgaande reeds is aangenomen ten gevolge van de loonsverhoging rechtstreeks, d. w. z. door het doorberekenen van deze loonsverhoging, doch ook om de reële inkomensdaling, die deze directe prijsverhoging voor hen betekent, geheel of gedeeltelijk op te vangen. Er zal zich in het maatschappelijk bestel een zeker sociaal evenwicht trachten te verwezenlijken, hetgeen betekent dat de stijging van de lonen aanleiding zal gevén tot een procentueel even grote stijging van de overige binnenlandse kostenelementen. Een loonstijging van $1 \%$ zal, indien men met deze tendenties rekening houdt, een prijsstijging tot gevolg hebben van 
$0,7 \%$, aangezien het aandeel van alle binnenlandse kosten in de prijzen onzer producten ongeveer $70 \%$ bedraagt. Deze vrij aanmerkelijk hogere prijsstijging zal nauwkeurig dezelfde gevolgen hebben voor onze betalingsbalans als hierboven is aangegeven voor de prijsstijging van $0,3 \%$, doch in de verhouding van 7 tot 3 vergroot. Dientengevolge zal ook de inkrimping van de binnenlandse activiteit, die nodig is om daarbij de betalingsbalans niet verder uit haar evenwicht te brengen, evenredig groter moeten zijn, hetgeen betekent dat deze ca $0,85 \%$ zal dalen. Onder deze omstandigheden zal een loonstijging van $1 \%$ dan ook leiden tot een vermindering van de werkgelegenheid met $0,85 \%$.

\section{Wat is met verhoging van de arbeidsproductiviteit te bereiken?}

Kunnen de ongunstige werkingen van de loonsverhoging voor de betalingsbalans wellicht worden voorkomen door de loonsverhoging te doen gepaard gaan met een verhoging van de arbeidsproductiviteit?

Deze vraag heeft zich terecht de vakbeweging bij de jongste onderhandelingen over de $5 \%$ loonsverhoging gesteld en men is tot het inzicht gekomen dat dit inderdaad het geval is. Terecht, want indien naast $5 \%$ loonsverhoging bv. ook $5 \%$ stijging van de arbeidsproductiviteit zou optreden, zal aan de loonkosten per eenheid product niets veranderen en is daardoor de noodzaak tot prijsverhoging voor de ondernemer ook weggenomen. Dit betekent dat dan ook in het licht van bovenstaande redenering geen vermindering van de binnenlandse productie nodig zal zijn om de betalingsbalans in dezelfde positie te houden; bij onveranderde prijzen verandert er aan de uitvoer ook niets en is er geen behoefte de invoer daarbij aan te passen.

Wat betekent dit nu voor de werkgelegenheid?

Het betekent opnieuw dat - afgezien van een gelukkige bijzondere omstandigheid die zich juist thans voordoet, en waarover zo dadelijk meer - de werkgelegenheid bedreigd wordt als gevolg van de loonsverhoging. Want daar dan per uur en per man $5 \%$ meer wordt gepresteerd, terwijl toch de binnenlandse productie dezelfde moet blijven om de betalingsbalans niet verder uit haar evenwicht te brengen, zal de werkgelegenheid met $5 \%$ dalen.

Dit zal zelfs automatisch geschieden, nl. buiten de financiële autoriteiten om. De prijzen immers veranderen niet. Daardoor verandert, zoals reeds gezegd, ook niet onze uitvoer. En het laat zich 
bewijzen dat ook de binnenlandse afzet op den duur niet zal veranderen. Deze toch wordt bepaald door de totale uitgaven van de Nederlandse bevolking, die weer afhankelijk zijn van het nationale inkomen. Dit nationale inkomen is afhankelijk van de prijzen, die niet veranderen, de buitenlandse afzet, die ook niet verandert en de binnenlandse afzet. De binnenlandse afzet is dus uiteindelijk slechts afhankelijk van een aantal factoren die niet veranderen ( $p r i j z e n$, buitenlandse afzet) en verandert daarom ook niet ${ }^{5}$ ).

Deze ongunstige gevolgen van de loonsverhoging behoeven slechts dan niet gevreesd te worden, wanneer de totale binnen- en buitenlandse vraag toch hoger is dan bij de oude stand van de arbeidsproductiviteit en bij practisch volledige werkgelegenheid kan worden geproduceerd. Dit is de gelukkige omstandigheid, waarop zo juist werd gedoeld: er is aanleiding om te geloven dat na de devaluatie zulks in beginsel het geval was. De vraag van de zijde van het buitenland is door de devaluatie aanzienlijk gestimuleerd en overtreft op verschillende punten in het bedrijfsleven de productiecapaciteit. Daarom is het voorshands zeer toe te juichen dat gestreefd wordt naar verhoging van de arbeidsproductiviteit ter compensatie van de loonsverhoging.

Dit proces heeft echter een grens. Stellen wij dat de totale vraag de productie bij volledige werkgelegenheid en bij de oude productiviteit met $5 \%$ overschrijdt, dan zal een stijging van $5 \%$ in de arbeidsproductiviteit nuttig en wenselijk zijn: er kan dan aan de gestegen buitenlandse vraag worden voldaan en het loon kan zonder schade een verhoging van $5 \%$ ondergaan.

Bedraagt die stijging bv. $7 \%$, dan zal er echter in beginsel $2 \%$ werkloosheid ontstaan. Dan is dus het ogenblik aangebroken waarop een verdere productiviteitsstijging schadelijk wordt voor de werkgelegenheid. $\mathrm{Zij}$ zal eerst dan weer nuttig zijn, wanneer zij gepaard gaat met een vermeerdering van onze buitenlandse afzet.

5) Dit bewijs is wat moeilijk te volgen voor wie niet gewend is aan een wiskundige gedachtengang. Het is nl. een geval waarbij tussen een aantal grootheden een aantal gelijktijdige (simultane) vergelijkingen bestaan. Geeft men het prijsniveau aan met $p$, de witvoer met $E$, de totale uitgaven van de Nederlandse bevolking met $X$, het nationale inkomen met $Y$, dan kan men constateren dat $X=f(Y, p)$, terwijl tevens $Y=g(X, U, p)$. Vult men nu de tweede relatie in in de eerste, dan blijkt dat

$$
\mathrm{X}=\mathrm{f}\{\mathrm{g}(\mathrm{X}, \mathrm{U}, \mathrm{p}), \mathrm{p}\}=\mathrm{h}(\mathrm{X}, \mathrm{U}, \mathrm{p})
$$

is, wasruit men. $X$ kan "oplossen": $X: k(U, p)$. Omdat $U$ en $p$ niet veranderen bij loonsverhoging met gelijktijaige even grote verhoging van arbeidsproductiviteit, verandert $X$ dus ook niet. 
Deze laatste toch bepaalt in de grond de mogelijkheden van onze invoer en daardoor van onze productie-omvang. Een zodanige verhoging van de buitenlandse afzet zal dan alleen kunnen worden bereikt indien tegelijkertijd een prijsdaling optreedt. Dit is bij verhoging van de arbeidsproductiviteit mogelijk, mits deze laatste niet met een gelijke loonstijging gepaard gaat.

Samenvattend zien wij dus dat het wegnemen van de ongunstige gevolgen van een loonstijging voor de werkgelegenheid door een even grote verhoging van de arbeidsproductiviteit slechts mogelijk is, voorzover wij aan de totale vraag door de devaluatie geschapen niet zouden kunnen voldoen. Van het ogenblik af, waarop aan deze totale vraag voldaan is, zou een verdere verhoging van de lonen, ook wanneer $z$ ij met een even grote verhoging van arbeidsproductiviteit gepaard gingen, weliswaar de betalingsbalans ongemoeid laten, maar de werkgelegenheid/schaden.

De werkgelegenheid kan slechts weer verder groeien indien de productiviteitsstijging de loonstijging overtreft; geschiedt dit niet, dan kan zij alleen groeien in de mate waarin de buitenlandse vraag toeneemt, of in de mate waarin wij in staat zijn invoervervangingen toe te passen. Wij komen daarmede op het bekende programma van de industrialisatie in de zin van produceren van nieuwe goederen of van goederen in nieuwe kwaliteiten. Een programma dat moeilijk door loonpolitiek kan worden beïnvloed.

\section{Conclusies.}

Geven wij nog een algemene samenvatting van ons betoog. Het blijkt dat de invloed, die van een loonsverhoging uitgaat op de werkgelegenheid, onder verschillende omstandigheden ook verschillend is.

Wanneer een land zich de weelde kan veroorloven een verhoging van het loon toe te passen zonder dat daarbij ter bescherming van de betalingsbalans zekere tegenmaatregelen nodig zijn, dan is vooral op korte termijn bezien de invloed van de loonsverhoging op de werkgelegenheid slechts gering te achten.

Wanneer echter maatregelen tot het handhaven van de betalingsbalanspositie onafwijsbaar nodig zijn, liggen de zaken anders. In het gunstigste geval, nl. wanneer de andere groepen van de bevolking passief blijven, zal een verlaging van de werkgelegenheid optreden die in procenten ongeveer $0,37 \times$ de loonsverhoging uitmakkt. Indien de andere groepen der bevolking zich echter inspan- 
nen om hun positie evenredig aan die der werkende arbeiders te verbeteren, dan dreigt een werkloosheid van ca $0,85 \times$ de loonsverhoging.

De ongunstige gevolgen ener loonstijging yoor de betalingsbalans kunnen worden te niet gedaan door een even grote stijging van de arbeidsproductiviteit. Zolang een toestand van volle werkgelegenheid of zelfs overspanning van de arbeidsmarkt bestaat, is dit alleen maar een voordeel. Op dit ogenblik is de situatie ongeveer zo en is een stijging van de arbeidsproductiviteit dan ook zeer toe te juichen. In een iets later tijdsgewricht kan het anders liggen. Dan zal het dus niet mogelijk zijn om elke gewenste loonsverhoging "onschadelijk" te maken door een evengrote stijging van de arbeidsproductiviteit. Wat men dan doet is nl. wèl onschadelijk voor de betalingsbalans, maar schadelijk voor de werkgelegenheid. Wel kan men deze schadelijke gevolgen opvangen door een verhoging van de arbeidsproductiviteit die (voldoende) groter is dan de loonsverhoging. Men zal zich dus bij de toekomstige loonpolitiek door deze overwegingen moeten laten leiden en die moeten afstemmen op de mogelijkheden t.a.v. de werkgelegenheid. 